\title{
Introduction to the special issue: the phase I CORDEX RegCM4 hyper-matrix (CREMA) experiment
}

\author{
Filippo Giorgi
}

Received: 20 March 2014 / Accepted: 3 April 2014 /Published online: 11 June 2014

(C) Springer Science+Business Media Dordrecht 2014

\section{The CREMA experiment}

This special issue of Climatic Change gathers a series of papers detailing the first analysis of the Phase I CORDEX RegCM4 hyper-Matrix (or CREMA) experiment. CORDEX (COordinated Regional Downscaling Experiment) is a newly implemented modeling framework under the auspices of the World Climate Research Program (WCRP) whose goals are to: i) assess and improve different regional climate downscaling techniques; ii) produce a new generation of 21st century regional climate projections over regions worldwide; iii) foster the interactions between the climate science and end-user communities and in particular the involvement of scientists from developing countries (Giorgi et al. 2009; Jones et al. 2011). It is envisioned to achieve these objectives through the completion and analysis of large multi-model, multimethod simulations with different downscaling techniques (dynamical and empirical) using a common and intercomparable experiment framework. regional climate models (RCMs) are thus key components of the CORDEX initiative.

During the last decades a number of RCMs systems have been developed (e.g. Giorgi 2006; Rummukainen 2010). One of these is the RegCM system developed and maintained at the Abdus Salam International Centre for Theoretical Physics (ICTP). This model has evolved through successive versions (Dickinson et al. 1989; Giorgi et al. 1993a, b; Giorgi and Mearns 1999; Pal et al. 2007) up to the most recent RegCM4 (Giorgi et al. 2012). Over the last 25 years the RegCM has been applied to a wide range of studies by a large user community coordinated through the Regional Climate research NETwork, or RegCNET (Giorgi et al. 2006). The Phase I CREMA experiment represents the first contribution of the RegCNET modeling community to the CORDEX effort.

The Phase I CREMA experiment consists of a series of 34 scenario simulations completed with the RegCM4 over 5 CORDEX domains (see Table 1): Africa, Mediterranean, Central America, South America and South Asia. Each domain follows the CORDEX specifications (see Giorgi et al. 2009), with a horizontal grid spacing of $50 \mathrm{~km}$, and all simulations cover the period 1970-2100. In the CREMA experiment we attempted to cover, albeit in a limited way,

This article is part of a Special Issue on "The Phase I CORDEX RegCM4 Experiment MAtrix (CREMA)" edited by Filippo Giorgi, William Gutowski, and Ray W. Arritt.

F. Giorgi $(\bowtie)$

Abdus Salam International Centre for Theoretical Physics, Trieste, Italy

e-mail: giorgi@ictp.it 
different sources of uncertainty, namely the driving Global Climate Models (GCM), the greenhouse gas (GHG) Representative Concentration Pathways (RCP, Moss et al. 2010), and model physics configuration.

Therefore, scenario simulations were completed using different driving GCMs, RCPs, and model physics schemes.

The rationale behind the specific choices of these three simulation aspects was the following. Concerning RCPs, we selected the high end RCP8.5 and low end RCP4.5 scenarios (Moss et al. 2010), with a predominance of the former in order to obtain more pronounced change signals. For the driving GCMs, at the time of completion of the CREMA experiments we had available 7 GCMs with 6-hourly meteorological fields suitable for providing driving lateral boundary conditions for the RegCM4 simulations. Temperature, precipitation and low level circulation of each GCM were first assessed over the 5 CORDEX domains (see also Elguindi et al. 2014), and test experiments with the RegCM4 driven by each GCM were conducted to select the best performing GCMs over the respective domain. This lead to the final choice of 3 GCMs: HadGEM2-ES (with a horizontal resolution of $\sim 1.5^{\circ}$ ), MPI-ESM-MR (resolution of $\sim 1.9^{\circ}$ ), and GFDL-ESM2M (resolution of $\sim 2^{\circ}$ ). Not all three GCMs were used in each domain, since for some of the domain areas they did not perform well. For example, HadGEM2-ES was not used for the South Asia domain runs because it had an excessively weak monsoon rain-belt, which lead to excessively weak monsoon rain also in the nested RegCM4.

Finally, in terms of model physics configurations, the RegCM4 system includes multiple options for all physics representations (land surface processes, cumulus convection and resolvable scale precipitation, planetary boundary layer and radiative transfer, see Giorgi et al. 2012). A large number of preliminary tests with different physics schemes over the various domains were conducted with boundary conditions from the different GCMs, and only those configurations yielding the most realistic climatologies were chosen. As shown in

Table 1 List of the RegCM4 CREMA simulations identified by their driving GCM, RCP and convection/land surface scheme. HAD, MPI and GFDL indicate that the driving GCM used is HadGEM-2ES, MPI-ESM-MR, GFDL-ESM2M, respectively; G, E, GE indicate that the convection scheme used is Grell, Emanuel and mixed (Grell over land, Emanuel over ocean) respectively; BATS, CLM indicate that the land surface scheme used is BATS, CLM, respectively; 8.5 and 4.5 indicate that the representative concentration pathway used is RCP8.5, RCP4.5, respectively. The number in parenthesis for the Mediterranean domain indicates the number of scenario runs completed by using different parameters within the convection and/or land surface scheme selected

\begin{tabular}{llllll}
\hline & Africa & Central America & India & Med. & South America \\
\hline HAD-CLM-E & & $4.5,8.5$ & & & $4.5,8.5$ \\
HAD-CLM-GE & $4.5,8.5$ & & 8.5 & \\
HAD-BATS-G & & $4.5,8.5$ & & 8.5 & \\
HAD-BATS-G & & $4.5,8.5$ & & $8.5(2)$ & \\
HAD-BATS-GE & & & $8.5(3), 4.5$ & $4.5,8.5$ \\
MPI-CLM-E & & 8.5 & 8.5 & & 8.5 \\
MPI-CLM-GE & & & & 8.5 & \\
MPI-BATS-G & 8.5 & 8.5 & & 8.5 & \\
HAD-BATS-E & & & & $8.5(2)$ & \\
MPI-BATS-GE & & & $4.5,8.5$ & & \\
GFDL-CLM-E & & & $4.5,8.5$ & & \\
GFDL-CLM-GE & & & & & \\
\hline
\end{tabular}


Table 1, at the end of this process different combinations of two land surface schemes (the Biosphere-Atmosphere Transfer Scheme, or BATS, Dickinson et al. 1993; and Community Land Model, CLM3.5, Oleson et al. 2008) and two cumulus convection schemes (the schemes of Grell 1993 and Emanuel and Rothman-Zivkovich 1999, along with their combined use, i.e. Grell over land and Emanuel over ocean) were selected based on their best performance (in terms of temperature, precipitation and low level circulations) over a given domain. It is worth to mention that considerable effort went into the testing and selection of the model configurations, and this effort lead to the final outcome shown in Table 1. It can be seen that different numbers of simulations were conducted for the different domains, and this was also based on the availability of computing resources. For example, the largest (smallest) number of simulations is for the smallest (largest) domain, i.e. the Mediterranean (Africa).

The scenario runs were completed during 3 months in the summer of 2012 on 512 dedicated processors of a large cluster available at the ARCTUR High Performance Computing Centre in Goriansko, Slovenia, and about 160 Terabytes of data were produced and archived. During this period and following months, students and post-doctoral fellows were invited to ICTP from CICESE (Centro de Investigation Cientifica y de Education Superior de Ensenada), Mexico; University of San Paolo, Brazil; Indian Institute of Technology, India; Lotvos University, Hungary; and University of Dakar, Senegal, to carry out the simulations and subsequent analysis, so that the CREMA effort is a truly multi-institution collaborative one across the RegCNET network. The papers in this Special Issue, which are briefly introduced in the next section, are the result of the first analysis of the CREMA experiments.

\section{Papers appearing in the special issue}

The issue opens with a paper, Elguindi et al. (2014) which provides a basic comparative analysis of the CMIP5 GCMs (Taylor et al. 2012) over the 5 CORDEX domains in the CREMA experiment. It serves to place the three selected GCMs used in CREMA within the context of the broader CMIP5 ensemble, and it shows in particular how the three selected GCMs are among the best performers (based on a multiple metric approach) within the ensemble, thus justifying their selection The next two papers, Coppola et al. (2014) and Giorgi et al. (2014) provide an overall view of the entire CREMA ensemble of global and corresponding regional model simulations. They serve as basic references for more detailed analyses over individual domains presented in the other papers of the issue and in eventual future papers using this ensemble. Specifically, Coppola et al. (2014) present a baseline analysis of model systematic biases and future changes in temperature and precipitation mean climatologies over the various domains, while Giorgi et al. (2014) provide a corresponding analysis for a range of temperature and hydroclimatic extremes.

The issue then includes a series of papers focusing on the individual domains. Guttler et al. (2014) first assess the energy budget of the model over the Mediterranean domain; Mariotti et al. (2014) focus on the changes in intraseasonal and seasonal characteristics of monsoon climates over the Africa domain; Diro et al. (2014) report an analysis of changes in different characteristics of tropical cyclones over the Central Amrica domain (this being the first time that such an analysis is carried out for the RegCM4 system); the papers by da Rocha et al. (2014) and Llopart et al. (2014) examine the model simulations over the South America domain in terms of climate response to el Nino conditions and land-atmosphere interactions.

Without going into a more detailed description of the individual papers, a few general lessons were learned from this first CREMA experiment. The first is that no model physics configuration was found that performed optimally over all domains and for all driving GCMs. 
In other words, different physics configurations needed to be used for the different domains and driving GCM in order to optimize the model performance. This can perhaps be seen as a limitation of the RegCM4 physics schemes but also as an advantage of the flexibility offered by the availability of multiple physics options in the model. It also implies that the off-the-shelf configuration of the model may not be the best for a given application and that careful model validation and customization is needed in order to optimize the model performance.

The second lesson is that not only the model systematic errors but also the change signals were substantially dependent on the model physics configuration. Although the ensemble average large scale patterns of change (e.g. precipitaiton) were similar in the global and regional model CREMA ensembles (Coppola et al. 2014), in many individual domain cases the sensitivity to model configuration was large, and in some cases even larger than the sensitivity to driving GCM. This was particularly the case for tropical domains, to the point that two different configurations might almost be considered as different RCMs. On the one hand this implies that the internal model physics and variability contributes substantially to the simulation of changes, and on the other it adds an important element of uncertainty in the production of regional projections with RCMs, calling for the large multi-model approach envisioned in the CORDEX framework.

The third important lesson concerns the issue of "added value" of using RCMs. This is perhaps the single most important issue in regional climate modeling, which arises virtually in every RCM application. What we found in the CREMA experiments is that the added value is not necessarily to be found when looking at climatological means, which depend more on the physics of the specific models rather than the model resolution, but rather in higher order statistics and regional circulation features/feedbacks. For example, compared to the driving GCMs, the RegCM4 consistently improved the simulation of the tails of the daily (Giorgi et al. 2014) and seasonal (Coppola et al. 2014) precipitation distributions, while not systematically improving the climatological means (Coppola et al. 2014). As another example, the RegCM4 simulated much more realistic characteristics of African Easterly Wave activity compared to the driving GCMs, and this affected the simulation of precipitation changes over the West Africa region (Mariotti et al. 2014).

As mentioned, the papers in the special issue only offer an initial analysis of the wealth of data produced in this Phase I CREMA experiment and further analysis is currently under way to be reported in future work. The output from these experiments is being made available to the CORDEX data nodes for use by the regional climate research community in model evaluation studies, inter-comparisons with other CORDEX experiments and eventual use in impact assessment studies. In addition, we plan to incrementally populate the CREMA ensemble with new RegCM4 simulations as a continuing contribution of the RegCNET community to the CORDEX effort.

Ackowledgments I would like to thank all the contributors to this special issue for their huge effort in completing the simulations and analysis of the CREMA phase I experiment. Thanks also go to the CMIP5 global model groups for making available their products and to the ARCTUR computing centre for its computational support. Part of this work was supported by grants from the NEXTDATA project of the Italian Consiglio Nazionale per la Ricerca (CNR) under the auspices of the Ministry of Education, University and Research. Finally, I would like to thank W. Gutowski and R. Arritt for acting as co-guest editors of this issue.

\section{References}

Coppola E, et al. (2014) Present and future climatologies in the Phase I CREMA experiment. Climatic Change, this issue 
Da Rocha RP, et al. (2014) Interannual variability associated with ENSO: Present and future climate projections of RegCM4 for the South America CORDEX domain. Climatic Change. doi:10.1007/S10584-014-1119-y

Dickinson RE, Errico RM, Giorgi F, Bates GT (1989) A regional climate model for the western United States. Clim Chang 15:383-422

Dickinson RE, Henderson-Sellers A, Kennedy PJ (1993) Biosphere - Atmosphere Transfer Scheme, BATS: version $1 \mathrm{E}$ as coupled to the NCAR Community ClimateModel. Technical Note NCAR/TN $-387+\mathrm{STR}$, $72 \mathrm{p}$

Diro GT, et al. (2014) Tropical cyclones in a regional climate change projection with RegCM4 for the CORDEX Central America domain. Climatic Change, this issue.

Elguindi N, Giorgi F, Turuncoglu UU (2014) Assessment of CMIP5 global model simulations over the sub-set of CORDEX domains used in the Phase I CREMA Experiment. Climatic Change. doi:10.1007/S10584-0130935-9

Emanuel KA, Rothman-Zivkovich MZ (1999) Development and evaluation of a convection scheme for use in climate models. J Atmos Sci 56:1756-1782

Giorgi F (2006) Regional climate modeling: status and perspectives. J Phys IV 139:101-118

Giorgi F, Mearns LO (1999) Introduction to special section: regional climate modeling revisited. J Geophys Res 104:6335-6352

Giorgi F, Marinucci MR, Bates G (1993a) Development of a second generation regional climate model (regcm2): boundary layer and radiative transfer processes. Mon Weather Rev 121:2794-2813

Giorgi F, Marinucci MR, Bates G, DeCanio G (1993b) Development of a second generation regional climate model (RegCM2), part II: convective processes and assimilation of lateral boundary conditions. Mon Weather Rev 121:2814-2832

Giorgi F et al (2006) Introduction to the TAC special issue: The RegCNET network. Theor Appl Climatol 86:1-4

Giorgi F, Jones C, Asrar G (2009) Addressing climate information needs at the regional level: the CORDEX framework. WMO Bull 175-183

Giorgi F et al (2012) RegCM4: model description and preliminary tests over multiple CORDEX domains. Clim Res 52:7-29

Giorgi F, et al. (2014) Changes in extremes and hydroclimatic regimes in the CREMA ensemble projections. Climatic Change. doi:10.1007/S10584-014-1117-0

Grell GA (1993) Prognostic evaluation of assumptions used by cumulus parameterizations. Mon Weather Rev 121:764-787

Guttler I, Brankovic C, Srnec L, Patarcic M (2014) The impact of boundary forcing on RegCM4.2 surface energy budget. Climatic Change. doi:10.1007/S10584-0.13-0995-x

Jones C, Giorgi F, Asrar G (2011) The COordinated regional downscaling EXperiment: CORDEX. An international downscaling link to CMIP5. CLIVAR Exch 16:34-40

Llopart MP, Coppola E, Giorgi F, Da Rocha RP, Cuadra SV (2014) Climate change impact on precipitation for the Amazon and La Plata basins. Climatic change. doi:10.1007/S10584-014-1140-1

Mariotti L, Diallo I, Coppola E, Giorgi F (2014) Seasonal and intraseasonal changes of Africa monsoon climates in 21st century CORDEX projections. Climatic Change. doi:10.1007/S10584-014-1097-0

Moss RH et al (2010) The next generation of scenarios for climate change research and assessment. Nature 463 : $747-756$

Oleson $\mathrm{K}$ et al (2008) Improvements to the community land model and their impact on the hydrological cycle. J Geophys Res 113:G01021. doi:10.1029/2007JG000563

Pal JS et al (2007) The ICTP RegCM3 and RegCNET: regional climate modeling for the developing world. Bull Am Meteorol Soc 88:1395-1409

Rummukainen M (2010) State-of-the-art with regional climate models. Wiley Interdiscip Rev 1:82-96

Taylor KE, Stouffer RJ, Meehl GA (2012) An overview of CMIP5 and the experiment design. Bull Am Meteorol Soc 78:485-498 